\title{
Physiotherapy intervention as a complementary treatment for people living with HIVIAIDS
}

\author{
This article was published in the following Dove Press journal: \\ HIVIAIDS - Research and Palliative Care \\ 2 June 2014 \\ Number of times this article has been viewed
}

\author{
Sara D Pullen' \\ Nnenna Nina Chigbo ${ }^{2}$ \\ Emmanuel Chukwudi \\ Nwigwe ${ }^{2}$ \\ Chinwe J Chukwuka ${ }^{3}$ \\ Christopher Chim Amah ${ }^{4}$ \\ Stanley C Idu ${ }^{2}$ \\ 'Department of Rehabilitation \\ Medicine, Division of Physical \\ Therapy, Emory University, \\ Atlanta, GA, USA; ${ }^{2}$ Department \\ of Physiotherapy, ${ }^{3}$ Department \\ of Medicine, ${ }^{4}$ Paediatric Surgery \\ Division, Department of Surgery, \\ College of Medicine, University of \\ Nigeria Teaching Hospital, Enugu, \\ Nigeria
}

Background: The advent of highly active antiretroviral therapy has dramatically extended the life expectancy of people living with human immunodeficiency virus (HIV)/acquired immunodeficiency syndrome. Despite this increased longevity, HIV disease and its pharmacological treatment can cause long-term and acute health complications, many of which can be treated successfully by physiotherapy. The purpose of this paper is to report the effect of a 12-week rehabilitation program on several health-related markers in a 43-year-old woman living with HIV.

Methods: This case study examined the effect of a 12-week exercise and manual therapy intervention on morphology, pain, cardiopulmonary fitness, strength, neurological balance, immune markers (CD4 cell count), and quality of life in a 43-year-old woman living with HIV.

Results: The results showed complete elimination of pain and shortness of breath on exertion. There was also a reduction in resting heart rate, waist circumference, exercise duration, muscle strength, and endurance. The patient showed an increase in peak expiratory flow rate, maximal heart rate attained, upper arm, forearm, and thigh circumference, and CD4+ cell count. The patient also showed improvements in the quality of life domains of general health, pain, energy/ fatigue, social and physical functioning, and emotional well-being.

Conclusion: Physiotherapy interventions consisting of exercise and manual therapy appear beneficial in several areas as an adjunct therapy in HIV management.

Keywords: exercise, manual therapy, quality of life

\section{Introduction}

The past 20 years have seen a marked rise in the prevalence of people living with human immunodeficiency virus (HIV) and acquired immunodeficiency syndrome (AIDS) due to new infections as well as improved disease management leading to increased life expectancy. Since the advent of highly active antiretroviral therapy (HAART) in 1996, treatment of people living with HIV/AIDS (PLWHA) has changed significantly. PLWHA in developed countries have a nearly normal life expectancy when given access to adequate treatment. ${ }^{1}$ In spite of these gains, the data show that a significant symptom burden continues to exist among PLWHA. ${ }^{2}$ This symptom burden can include chronic pain, neurological deficits, and musculoskeletal impairments. Noninfectious musculoskeletal complications are estimated to affect about $72 \%$ of the HIV-infected population. ${ }^{3}$ Common complications include osteopenia/osteoporosis, osteonecrosis, joint disease, myopathies, and metabolic disorders. ${ }^{4-6} \mathrm{HIV}$ infection is also associated with loss of lean body mass which may be related to difficulty exercising, poor nutrition, widespread pain, metabolic disturbances, and lipid abnormalities. ${ }^{7,8}$ This loss of lean body mass is commonly seen in muscle wasting of the extremities.
Correspondence: Sara D Pullen Emory University School of Medicine, Division of Physical Therapy, Department of Rehabilitation Medicine, I462 Clifton Road, NE, Suite 3/2, Atlanta, GA 30322, USA

$\mathrm{Tel}+\mathrm{I} 40471251 / 2$

Fax +I $4047 / 24130$

Email sara.pullen@emory.edu 
Another anthropometric change is the redistribution of body fat, often seen in the accumulation of abdominal fat. Neurological disorders can lead to slowed movement, ataxia, impaired gait, diminished fine motor skills, and various cognitive impairments. This constellation of physical symptoms can contribute to disability, sedentary behaviors, chronic pain, and decreased quality of life. ${ }^{9}$

O'Brien et al developed a framework of HIV-related disability known as episodic disability. ${ }^{10}$ This framework defines disability as multidimensional and episodic, with unpredictable periods of illness and wellness. ${ }^{10}$ Episodes of disability are characterized by these authors as "health-related setbacks that manifest from HIV disease, its treatments or conditions". ${ }^{10}$ Physiotherapy is often used to treat people at different stages of such impairment-causing setbacks, and therefore may be considered an antidote to this episodic disability, because it can help individuals at various stages of illness as well as prevent further disability. Physiotherapy has been shown to positively affect physical impairment, functional limitations, and quality of life issues in a wide range of patient populations with various diagnoses. ${ }^{11,12}$ However, the literature lacks well designed studies regarding the specific role of the physiotherapist in the treatment of PLWHA. The limited research available is mainly focused on exercise in PLWHA and does not examine the effectiveness of the full spectrum of skilled physiotherapy for treating HIV-related symptoms. Given this gap in the literature, it is necessary to develop comprehensive physiotherapy interventions for PLWHA and to understand the comorbidities experienced by this population.

There is growing evidence to support aerobic exercise and progressive resisted exercise as being safe and effective for HIV-infected individuals. ${ }^{13-19}$ In 2012, Botros et al reported that nutritional counseling and exercise can be effective in treating HIV-related fat redistribution and metabolic abnormalities, and can improve body composition, strength, and fitness in PLWHA. ${ }^{15}$ Gomes et al investigated the effects of physical exercise on perception of life satisfaction (using the Life Satisfaction Index) and on immunological function in PLWHA, concluding that a moderate-intensity physical exercise program improved life satisfaction for PLWHA and had no adverse immunologic effects. ${ }^{16}$

The purpose of this case study was to examine the effect of a 12-week rehabilitation program on morphology, cardiopulmonary fitness, strength, neurologic balance, immune markers (CD4 cell count), and quality of life in a 43-year-old woman living with HIV. The study took place in the department of physiotherapy at the University of Nigeria Teaching Hospital, Enugu, Nigeria.

\section{Materials and methods}

\section{Patient history and systems review}

The patient was a 43-year-old female who had been diagnosed with HIV 9 years earlier and had initiated a HAART medication regimen one year after her initial diagnosis. At the time of this study, the patient was on a HAART regimen of lamivudine, nevirapine, and zidovudine, and was followed monthly by her infectious diseases physician who was kept appraised of the patient's progress throughout the intervention. Apart from HIV, the patient had no other medical diagnoses. The patient volunteered for the study after attending a health promotion talk at the University of Nigeria Teaching Hospital. She signed an informed consent form to participate voluntarily in this study after guided ethical information was provided. The study was approved by the health research ethics committee at the hospital. Given her well managed HIV, lack of other comorbidities, and motivation, this patient was deemed an ideal candidate for the intervention.

The University of Nigeria Teaching Hospital is a 700-bed hospital with an exercise immunology unit housed within the physiotherapy department. This unit has a ventilated exercise intervention laboratory with two treadmills, two stationary bicycles, manual defibrillators, a multigym (resistive exercise system), blood pressure monitors, pulse oximeters, a portable supplemental oxygen tank, and peak flow meters.

\section{Examination}

The patient underwent a one-hour evaluation during which baseline measurements were taken using the following assessment tools: a ten-repetition maximum (10RM) to address strength, the timed "Up and Go" (TUG) test and Berg Balance Scale (BBS) for assessment of balance, application of the Karvonen formula for heart rate reserve, and measurement of thigh, upper arm, and waist circumference. ${ }^{20-22}$ Blood samples were taken to determine the patient's CD4 counts.

On initial evaluation, the patient's primary complaints were of pain, weakness, and decreased endurance. She reported upper and lower back pain of 10/10 on a visual analog scale. The patient's mid trapezius, erector spinae, and latissimus dorsi all showed increased muscle density and tenderness to palpation. She also complained of shortness of breath on mild exertion, such as when grocery shopping or cleaning her single-storeyed home. The patient reported that since her diagnosis of HIV she had been aware of anthropometric 
changes, including redistribution of fat (increased belly fat) and muscle wasting (thinning and decreased musculature of the extremities). The patient reported occasional loss of balance with exertion, fatigue, and low self-esteem. Medical clearance was obtained from her physician in the HIV clinic of the hospital and pre-intervention measurements were taken at the exercise immunology unit. Three measurements per physical parameter were taken by two separate physiotherapists to ensure interobserver and intraobserver validity. The patient's physiotherapy goals were as follows: to increase muscle strength in the extremities; to eliminate pain; and to increase endurance so that she would not become short of breath on mild exertion (ie, when going grocery shopping or cleaning her house).

CD4 lymphocytes are the primary targets of HIV, with the $\mathrm{CD} 4$ count (number of $\mathrm{CD} 4$ cells per $\mathrm{mL}$ of blood) defining the degree of immunocompromise, ie, the lower the CD4 count, the worse the immunocompromise. The CD4 count is used to stage the patient's disease, determine the risk of opportunistic illness, assess prognosis, and guide decisions about when to start antiretroviral therapy. ${ }^{23,24} \mathrm{~A}$ healthy, nonimmunocompromised person's CD4 count is expected to be $500-1,000$ cells $/ \mathrm{mm}^{3} .{ }^{25}$ When a PLWHA's antiretroviral medication is at therapeutic levels, that person's CD4 levels may still be in the "healthy" range. ${ }^{25}$ An individual is deemed to have progressed from HIV to AIDS when the CD4 count falls to below 200 cells $/ \mathrm{mm}^{3}{ }^{26}$ At the time of initiation of physiotherapy, our patient's CD4 count was 612 cells $/ \mathrm{mm}^{3}$.

At initial evaluation, the patient's resting heart rate was 104 beats per minute. Her maximum age-predicted heart rate was calculated to be 177 beats per minute using the formula: 220 - patient age. Heart rate reserve was calculated using the Karvonen formula $\left(\mathrm{HR}_{\max }-\mathrm{HR}_{\text {rest }}\right)$, as $177-104=73 .^{22}$ To determine the maximum heart rate attainable on exercise at her initial evaluation, the patient was instructed to walk or run on the treadmill for as long as she could. She was able to attain a heart rate of 128 beats per minute at a speed of 5.4 $\mathrm{km} /$ hour and at an inclination of 14 . She stopped at 6 minutes and 17 seconds. She was asked to rate her exertion using the modified Borg's Rate of Perceived Exertion scale ( 0 , none; 20 , maximal) on which the patient gave a rating of $4 .{ }^{23} \mathrm{Her}$ peak expiratory flow rate was $240 \mathrm{~L} / \mathrm{min}$, her maximal oxygen uptake was $22.5 \mathrm{~mL} / \mathrm{kg} / \mathrm{min}$, and her metabolic equivalents were 6.6. Strength was assessed using the mean of a 10RM. The patient's 10RM for biceps curl, pull-down, chest press, leg extension, and hamstring curl measurements are listed in Table 1.
Table I Change in cardiovascular fitness, muscle strength, endurance, and immunologic values after physiotherapy intervention

\begin{tabular}{|c|c|c|c|}
\hline Variable & $\begin{array}{l}\text { Pre- } \\
\text { intervention }\end{array}$ & $\begin{array}{l}\text { Post- } \\
\text { intervention }\end{array}$ & $\begin{array}{l}\text { Percent } \\
\text { change }\end{array}$ \\
\hline \multicolumn{4}{|c|}{ Cardiovascular/cardiopulmonary fitness } \\
\hline $\begin{array}{l}\text { Resting heart rate, mean } \\
\text { (bpm) }\end{array}$ & 104 & 100 & -4 \\
\hline $\begin{array}{l}\text { Maximum heart rate, } \\
\text { mean }(\mathrm{bpm})\end{array}$ & 128 & 148 & 15.63 \\
\hline $\begin{array}{l}\text { Peak expiratory flow rate, } \\
\text { mean (L/min) }\end{array}$ & 240 & 450 & 87.5 \\
\hline $\begin{array}{l}\text { Exercise duration, mean } \\
\text { (minutes) }\end{array}$ & 6.03 & 12.02 & 97.8 \\
\hline $\begin{array}{l}\text { Maximal oxygen uptake, } \\
\text { mean }\end{array}$ & 22.5 & 48.7 & 116.4 \\
\hline $\begin{array}{l}\text { Metabolic equivalents, } \\
\text { mean }\end{array}$ & 6.6 & 14 & 112.1 \\
\hline \multicolumn{4}{|c|}{ Muscle strength and endurance $(\mathrm{kg})$} \\
\hline Biceps curl & 11.25 & 24.75 & 120 \\
\hline Pull-down & 15.75 & 20.25 & 28.57 \\
\hline Chest press & 11.25 & 15.75 & 40 \\
\hline Leg extension & 15.75 & 20.25 & 28.57 \\
\hline Hamstring curl & 6.75 & 11.25 & 66.67 \\
\hline \multicolumn{4}{|l|}{ Immunology } \\
\hline CD4 cell count $\left(\right.$ cell $\left./ \mathrm{mm}^{3}\right)$ & 612 & 689 & 12.58 \\
\hline \multicolumn{4}{|l|}{ Anthropometry $(\mathrm{cm})$} \\
\hline Waist circumference & 102.1 & 96.52 & 5.47 \\
\hline Upper arm circumference & 24.0 & 26.0 & 8.33 \\
\hline Thigh circumference & 48.7 & 49.0 & 0.62 \\
\hline
\end{tabular}

Balance was assessed using the BBS and TUG tests. ${ }^{20,21}$ The two tests were set up as per their protocols, and performed and scored in the clinic at initial evaluation and at the end of the 12-week intervention. On initial examination, the patient scored 54 on the BBS, which does not indicate balance impairment as per the test scoring protocol ${ }^{20}$ Similarly, the patient scored 5.4 seconds for the pre-intervention TUG, so was in the "normal" category, ie, not at risk of falling. ${ }^{21}$ The BBS is a widely used balance assessment tool. The literature describes the utilization and effectiveness of this tool internationally, including in African countries such as Nigeria. ${ }^{27,28}$

Quality of life was assessed before and after the intervention using the Short Form-36 Health Survey (SF-36), a patientreported instrument assessing health and well-being. ${ }^{29}$ The SF-36 measures quality of life in the areas of overall vitality, physical functioning, mental health, pain, perception of general health, and physical, emotional, and social role functioning. ${ }^{29}$ The SF-36 is a generic tool that has been widely used in the context of HIV-related quality of life in Africa, is available in English and Afrikaans, ${ }^{30}$ and has been validated in Africa. ${ }^{31}$ Nigeria is a primarily English-speaking country and the patient spoke English as her first language, so the SF-36 
(and the entire intervention) was conducted in English. The patient completed the SF-36 in the clinic at her initial evaluation and at the end of the 12-week intervention.

The HERITAGE (HEalth, RIsk factors, exercise Training And Genetics) project is a long-term family study of the role of various hereditary and physiological variables in exercise tolerance and disease risk. With more than 170 publications emanating from its database, it is the longest and best controlled study of its type. ${ }^{32}$ HERITAGE has generated several studies of the effects of a 20 -week exercise program on several health-related variables. One such study reported that a 20 -week endurance program resulted in "small but significant" changes in body composition. ${ }^{32}$ In another study, a 20-week exercise program was associated with significant reductions in adiposity and abdominal fat. ${ }^{33}$ However, neither of these studies reported that a shorterduration exercise program would necessarily be more beneficial. Given the current research and the aims of the present study, a 12-week exercise program was deemed to be a realistic time frame.

After evaluation of her initial data, the following plan was established: 12 weeks of soft tissue massage to painful muscular areas, aerobic exercise to improve endurance, and resistive exercise to increase strength. Given that the patient's score on the TUG and BBS were all within normal limits, no specific balance intervention was planned. If the intervention was successful, the investigators hypothesized that the patient would show increased strength and endurance as well as anthropometric changes (decreased abdominal fat and increased musculature of the extremities). In addition, the investigators hypothesized that given these positive changes, the patient would have higher scores for quality of life measures due to increased confidence, less distress regarding anthropometric changes, and a sense of achievement.

Exercise, cardiopulmonary, and pain data were managed by entering the patient's progress and scores into a Microsoft Excel spreadsheet (Microsoft Corporation, Redmond, WA, USA), which was updated after each session and included mid-point laboratory values at 6 weeks. Percent changes were calculated manually on a hand-held calculator using the following formula: change from pre-intervention score to post-intervention score $\left(\right.$ score $_{\text {pre }}-$ score $_{\text {post }}=$ score $\left._{\text {change }}\right) /$ pre-intervention score $\times 100\left(\right.$ score $_{\text {change }} /$ score $_{\text {pre }} \times 100=$ percentage change).

The quality of life data from the SF-36 were scored and analyzed using the methods detailed in the SF-36 manual (version 1.0). Percentage scores were then derived manually using a calculator and a bar chart was developed using a Microsoft Excel spreadsheet.

\section{Intervention}

After her initial evaluation, the patient participated in a 12-week physiotherapy intervention consisting of manual therapy and aerobic and resistive exercise components. She exercised three times weekly for 30 minutes on nonconsecutive days. Two training sessions per week were supervised in the clinic by a physiotherapist, while the third session was home-based and confirmed by telephone on that day. The patient was allowed to progress at her own pace.

A physiotherapist performed soft tissue mobilization/ massage to the patient's upper and lower back to address her pain. Specific muscles targeted were the mid trapezius, erector spinae, and latissimus dorsi, because they were tender to palpation on evaluation and appeared to be the source of the patient's muscle pain. Massage was performed for the initial 2 weeks of the intervention, after which the patient had no further complaints of pain and the manual therapy component of the intervention ceased.

Aerobic exercise was performed at $50 \%-60 \%$ of the patient's heart rate reserve and the aerobic component of the intervention comprised 30-40 minutes of walking on the treadmill at the patient's own pace. The patient's heart rate was monitored during exercise sessions to ensure that she was exercising at the desired intensity. Oxygen saturation was measured at regular intervals using a hand-held pulse oximeter. The progression of the exercise intervention is described in Table 2.

For the strength training component of the intervention, five "multigym" training stations in the clinic were used to target large muscle groups: biceps curls (biceps), pull-downs (latissimus dorsi), chest press (pectorals), leg extension (quadriceps), and leg curls (hamstrings and gluteus maximus). The amount of weight could be adjusted in increments of $0.25 \mathrm{~kg}$ for each station. Resistance was increased throughout the program (Table 2). Initially, the patient lifted $60 \%$ of her 10RM; for example, her 10RM in pull-up was $11.25 \mathrm{~kg}$, so the patient started by lifting $60 \%$ of this weight, ie, $6.75 \mathrm{~kg}$. Throughout the 12 weeks, the patient gradually progressed at her own pace to $80 \%$ of her 10RM. With each increase in weight, the number of sets was reduced. The investigators allowed the patient to perform repetitions as her energy allowed for the different work stations; for example, she found training at some stations easier than others and thus performed increased sets/ repetitions at those stations. 
Table 2 Exercise intervention progression

\begin{tabular}{|c|c|c|c|}
\hline & $\begin{array}{l}\text { Aerobic exercise: percent } \\
\text { heart rate reserve }\end{array}$ & $\begin{array}{l}\text { Resistive exercise: number } \\
\text { of IORM sets }\end{array}$ & $\begin{array}{l}\text { Resistive exercise: percent } \\
\text { of IORM sets }\end{array}$ \\
\hline Week I & 50 & 5 & 60 \\
\hline Week 2 & 50 & $5-7$ & 60 \\
\hline Week 3 & 60 & 10 & 70 \\
\hline Week 4 & 60 & 10 & 70 \\
\hline Week 5 & 60 & $5-6$ & 80 \\
\hline Week 6 & 60 & $5-6$ & 80 \\
\hline Week 7 & 60 & $6-8$ & 80 \\
\hline Week 8 & 60 & $7-9$ & 80 \\
\hline Week 9 & 60 & $9-10$ & 80 \\
\hline Week 10 & 60 & 10 & 80 \\
\hline Week II & 60 & 10 & 80 \\
\hline Week 12 & 60 & 10 & 80 \\
\hline
\end{tabular}

Abbreviation: IORM, ten-repetition maximum.

Both aerobic and resistive exercises were performed after adequate warm-up and were followed by cool-down. For the aerobic component, warm-up and cool-down involved progressive walking on the treadmill for 3-5 minutes below the target heart rate. For the resistive component, warm-up and cool-down involved performing all joint movements without weights for 10 repetitions.

At each session, the patient was asked to report her pain level and to report if she had experienced any adverse effects after the previous session. At the halfway point (6 weeks of intervention), the patient underwent repeat laboratory tests to ensure that there were no adverse changes.

\section{Results}

Outcomes measured included self-reported pain on a visual analog scale, cardiovascular and cardiopulmonary function, strength, anthropometric changes, neurologic balance, and immunologic values. Subjective information was gathered verbally to compare with that at the initial evaluation. At the end of the 12-week intervention, the patient reported no further shortness of breath on mild exertion. She reported that she was able to do daily tasks such as housework and shopping in addition to moderate exercise without fatigue or shortness of breath. The patient did not report any specific or generalized body pain following the exercise sessions. She ceased to report any pain after the first 2 weeks of the intervention and from week 3 onwards she reported a score of 0 on the 10-point visual analog scale. SF-36 outcomes were measured as percent changes between pre-test and post-test scores, and there was a $72.5 \%$ positive change in the pain category. The patient reported marked improvement in apparent fat redistribution and muscle wasting, which greatly improved her self-esteem. The patient showed improvements in several cardiovascular and cardiopulmonary values, including resting heart rate, peak expiratory flow rate, exercise duration/endurance, and maximal oxygen uptake (Table 1). The patient reported that her experience in this study was favorable. Improvements in pain levels, selfesteem, physical appearance, and endurance contributed to her high satisfaction with the intervention.

At the end of the 12-week intervention, the patient achieved a heart rate of 148 beats per minute while walking on the treadmill for 12 minutes and 12 seconds at $6.7 \mathrm{~km} /$ hour with an inclination of 16 . Her exertion rating was 4 on the modified Borg's Rate of Perceived Exertion scale.

The patient showed increases in all areas of muscle strength and endurance. She had a $120 \%$ increase in number of biceps curls, a $28.6 \%$ increase in pull-downs, a $40 \%$ increase in chest presses, a $28.6 \%$ increase in leg extensions, and a $66.7 \%$ increase in hamstring curls (Table 1). Immunologically, the patient showed an increase in CD4 count from 612 cells $/ \mathrm{mm}^{3}$ (pre-intervention) to 689 cells $/ \mathrm{mm}^{3}$ (post-intervention), ie, a 12.6\% increase (Table 1). After the 12-week intervention, the patient scored 3.51 seconds on the TUG, representing a $35 \%$ improvement. The patient scored 56 points post-intervention on the BBS, indicating a 3.7\% improvement. Her results on the SF-36 reflected a positive change in all quality of life categories, ie, physical functioning, mental health, pain, and perception of general health, and physical, emotional, and social role functioning (Figure 1).

\section{Discussion}

With adequate pharmacologic and medical care, HIV can be a chronic disease rather than a fatal illness. With this new 


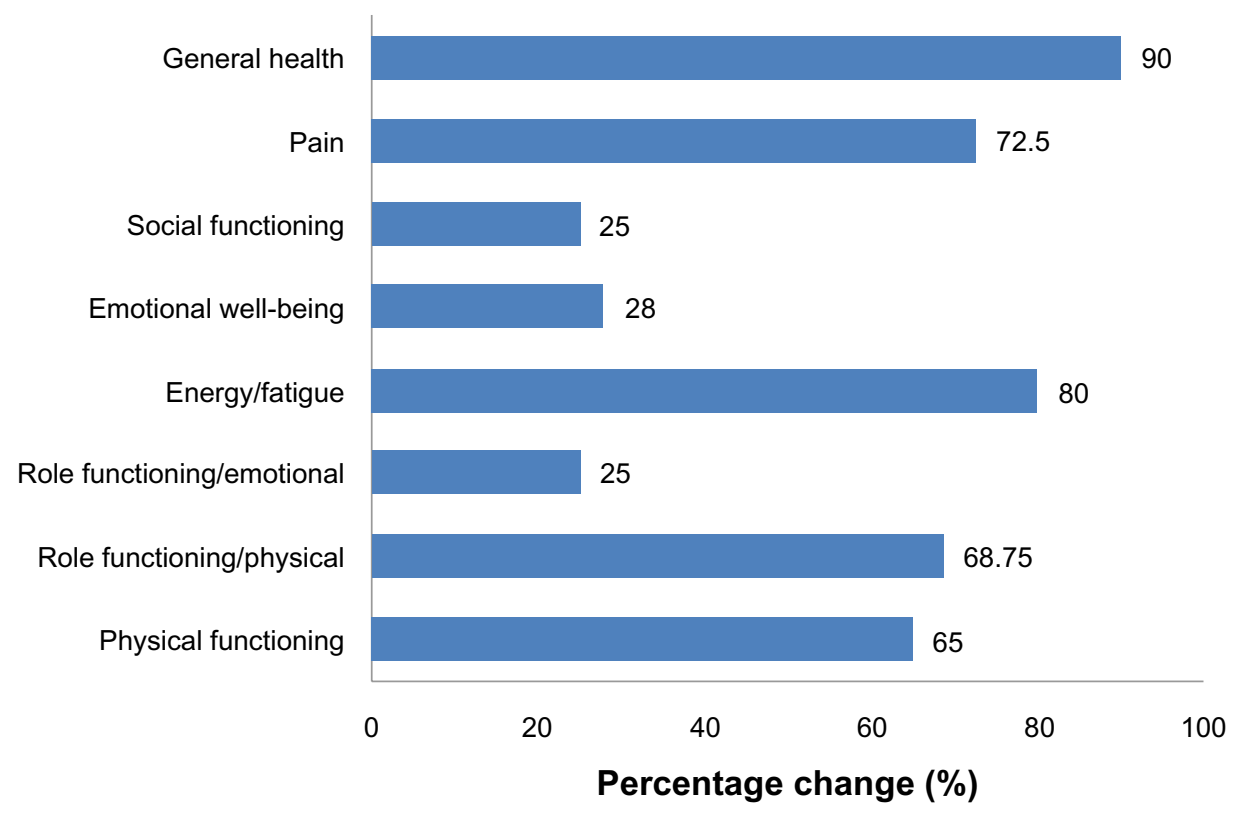

Figure I Percentage change in quality of life/health status domains on the Short Form-36 Health Survey.

disease classification has emerged a significant symptom burden of musculoskeletal, cardiovascular, neurologic, and pain-related impairments, many of which can be treated successfully with physiotherapy.

This case study shows that a 12-week intervention of manual therapy with aerobic and resistive exercise had positive effects in several categories of impairment in a 43-year-old woman with HIV who was compliant with her medication. The patient was an ideal candidate for this case study because she had no comorbidities and was highly motivated to participate. She volunteered willingly for the study and was therefore more likely to comply with all exercise interventions and to report back to the investigators. The patient exercised three times per week and underwent laboratory investigations at baseline, mid-way through the treatment period, and at the end of 12 weeks.

During this study, the patient showed slight improvement in her CD4 count. The US Department of Health and Human Services considers a change between two test results to be significant if there is a $30 \%$ change in absolute CD4 count. ${ }^{22}$ Our patient showed an increase in CD4 count from $612 \mathrm{cell} / \mathrm{mm}^{3}$ (pre-intervention) to $689 \mathrm{cell} / \mathrm{mm}^{3}$ (post-intervention), ie, a $12.6 \%$ increase. Because this was a single case study with no control, it is possible that this slight improvement in CD4 count could be due to the HAART regime and not necessarily the result of exercise. Although this improvement is not considered statistically significant per the US Department of Health and Human Services guidelines, it must be noted that the patient's CD4 count did not decrease and there was no adverse immunologic effect.

According to the literature, several methods can be used to establish clinically significant cut-off points. Although there is no official "gold standard" for clinically significant percentage change cut-off points across parameters, the Global Rating of Change is a well-documented scale commonly used in clinical research, including rehabilitation medicine. ${ }^{34,35}$ This scale requires the patient to assess her or his health status at the end of treatment and compare it with that at a previous time point, and then calculate the difference between the two assessments, eg, "a great deal worse" $(-7)$ to "a great deal better" $(+7)$. Our patient scored herself at +7 , thus rating herself at the topmost level of improvement.

At initial evaluation, the patient complained of 10/10 pain in her upper and lower back. After the 12-week intervention, the patient reported that she had no pain anywhere. This resolution in pain not only improved the patient's self-reported overall quality of life but also improved her ability to perform activities of daily living. Chronic pain is well documented to be a multifactorial process involving physiologic and psychosocial variables. Current research suggests that effective pain management should include a comprehensive and personalized treatment approach with pharmacological and nonpharmacologic interventions. ${ }^{36-39}$ Given that the patient ceased to have back pain after 2 weeks of manual therapy/massage and continued to be pain-free in addition to showing increases in strength, endurance, and overall self-esteem, it can be inferred that the elimination 
of pain was a multifactorial process, as suggested in the literature.

Nonpharmacologic pain management is well described, but is often discussed in combination with pharmacologic management. ${ }^{38,39}$ A systematic review in 2013 concluded that nonpharmacologic pain management techniques should be used only to supplement pharmacologic interventions, because empiric evidence supports pain medications as being the most effective for pain relief. ${ }^{36}$ Our patient reported an impressive decrease in pain from 10/10 (pre-intervention) to $0 / 10$ (post-intervention). It is noteworthy that managing pain with manual therapy and exercise does not have the risks associated with pharmacologic pain management and may be a safer alternative for addressing pain in certain patients.

The patient made favorable gains in cardiovascular and cardiopulmonary health, specifically resting heart rate, peak expiratory flow rate, exercise duration/endurance, and maximal oxygen uptake. At initial evaluation, the patient was unable to complete her daily tasks without shortness of breath. With her post-intervention cardiovascular and cardiopulmonary gains, the patient was able complete all her daily tasks and to undertake moderate exercise without shortness of breath or excessive fatigue.

The patient showed gains in strength, as evidenced by an increase in weights lifted and the number of repetitions that she was able to tolerate. She showed increases in both weights lifted and repetitions of exercises targeting the biceps, latissimus dorsi, pectorals, quadriceps, and hamstrings. The anthropometric changes seen in fat distribution (decrease in belly fat) and decreased muscle wasting (more defined musculature at the extremities) can be attributed to this positive change in strength as a result of her resistive exercise program. As the patient built up muscle bulk in her upper and lower extremities and decreased her abdominal fat, the appearance of wasting diminished and was replaced by defined musculature of the abdominals, biceps, quadriceps, and hamstrings.

Although the patient did not have impaired balance on the BBS and TUG tests, she did show a slight improvement at the final evaluation on both tests. No specific exercises were used to target balance; however, it can be assumed that her increase in strength and overall fitness contributed to the slight increase in score.

The SF-36 measures quality of life in areas related to health status and mental/social functioning. The greatest gains were seen in the areas of general health, pain, energy/ fatigue, and physical functioning (Figure 1). The patient's improvement in these quality of life measures can be attributed to her gains in all of the other areas examined in the study. Increased strength and endurance and decreased pain allowed the patient to perform activities of daily living and exercise without shortness of breath or excessive fatigue, thereby increasing her overall independence and enjoyment of daily activities. The positive anthropometric changes in abdominal fat and muscle wasting in the extremities increased her self-confidence, further improving her quality of life.

This case study shows the positive effects of a 12-week physiotherapy intervention in a 43-year-old woman living with HIV. The positive physical and quality of life effects of this intervention support the use of physiotherapy as a complementary treatment for people living with HIV/AIDS. Importantly, the 12-week intervention did not have any adverse immunologic effects in this patient. As a result of pharmacologic advances, HIV is now becoming a chronic disease rather than a fatal illness, so physiotherapists are likely to become increasingly important in the medical management of people living with HIV and AIDS. Future research is warranted to reproduce this type of study in a larger patient population. The patient in our case study was on a closely supervised antiretroviral medication regimen and her HIV disease had not yet progressed to AIDS.

This study has some limitations. The patient performed one of the three weekly exercise sessions at home, confirmed only by a telephone conversation on that day. Although we did attempt to ensure compliance by telephone call, this session was still managed externally by the patient. However, given her high motivation and compliance with the rest of the program, it is likely that the patient did indeed complete her home-based sessions.

At the midpoint of the intervention, the patient's laboratory results indicated no unfavorable changes. Our results may have been strengthened if the investigators had remeasured all strength and cardiopulmonary parameters at 6 weeks and compared the results with the 12-week data to determine if a 6-week program was more, less, or equally beneficial.

Given its case study nature, the conclusions of this report should not be overstated or generalized to a larger demographic, but rather be seen to reflect the positive outcomes for this individual patient. The case study reported here was an exploratory analysis of the effects of an exercise and manual therapy intervention on several markers in a patient living with HIV disease. Because only one participant was studied, a scale of effect must be considered and the conclusions should not be expanded to PLWHA in the general population. Despite these limitations, the case study 
is a convenient method for showing the effects of a physiotherapy intervention in an otherwise healthy individual living with HIV. More investigation is needed with regard to the safety and efficacy of physiotherapy for individuals at various stages of the disease so that best practices can be established for this population.

\section{Disclosure}

The authors report no conflicts of interest in this work.

\section{References}

1. Krashin DL, Merrill JO, Trescot AM. Opioids in the management of HIV-related pain. Pain Physician. 2012;15(3):157-168.

2. Newshan G, Bennett J, Holman S. Pain and other symptoms in ambulatory HIV patients in the age of highly active antiretroviral therapy. J Assoc Nurses AIDS Care. 2002;13(4):78-83.

3. Booth TC, Chhaya NC, Bell JG, Holloway BJ. Update on imaging of non-infectious musculoskeletal complications of HIV infection. Skeletal Radiol. 2012;41(11):1349-1363.

4. Ayaz AB, Paiement GD, Steinbach LS. Musculoskeletal manifestations of human immunodeficiency virus infection. $J$ Am Acad Orthop Surg. 2002;10(5):312-320.

5. Lima AL, Zumiotti AV, Camanho GL, et al. Osteoarticular complications related to HIV infection and highly active antiretroviral therapy. Braz J Infect Dis. 2007;11(4):426-429.

6. Takhar SS, Hendey GW. Orthopedic illnesses in patients with HIV. Emerg Med Clin North Am. 2010;28(2):335-342.

7. Thibault R, Cano N, Pichard C. Quantification of lean tissue losses during cancer and HIV infection/AIDS. Curr Opin Clin Nutr Metab Care. 2011;14(3):261-267.

8. Ene L, Goetghebuer T, Hainaut M, Peltier A, Toppet V, Levy J. Prevalence of lipodystrophy in HIV-infected children: a cross-sectional study. Eur J Pediatr. 2007;166(1):13-21.

9. Basavari KH, Navya MA, Rashmi R. Quality of life in HIV/AIDS. Indian J Sex Transm Dis. 2010;31(2):75-80.

10. O’Brien K, Davis A, Strike C, Young N, Bayoumi A. Putting episodic disability into context: a qualitative study exploring factors that influence disability experienced by adults living with HIV/AIDS. J Int AIDS Soc. 2009; 12(30):1-11.

11. Javier N, Montagnini M. Rehabilitation of the hospice and palliative care patients. J Palliat Med. 2011;14(5):638-648.

12. López-Sendín N, Alburquerque-Sendín F, Cleland JA, Fernández-delas-Peñas C. Effects of physiotherapy on pain and mood in patients with terminal cancer: a pilot randomized clinical trial. J Altern Complement Med. 2012;18(5):480-486.

13. Gale J. Physiotherapy intervention in two people with HIV or AIDS-related peripheral neuropathy. Physiother Res Int. 2003;8(4): 200-209.

14. Harris-Love MO, Shrader, JA. Physiotherapy management of patients with HIV-associated Kaposi's sarcoma. Physiother Res Int. 2004;9(4):174-181.

15. Botros D, Somarriba G, Neri D, Miller TL. Interventions to address chronic disease and HIV: strategies to promote exercise and nutrition among HIV-infected individuals. Curr HIV/AIDS Rep. 2012;9(4): 351-363.

16. Gomes RD, Borges JP, Lima DB, Farinatti PT. Effects of physical exercise in the perception of life satisfaction and immunological function in HIV-infected patients: non-randomized control trial. Rev Bras Fisioter. 2010;14(5):390-395.

17. O’Brien K, Nixon S, Tynan AM, Glazier R. Aerobic exercise interventions for adults living with HIV/AIDS. Cochrane Database Syst Rev. 2010;8:CD001796.
18. O’Brien K, Nixon S, Glazier R, Tynan AM. Progressive resistive exercise interventions for adults living with HIV/AIDS. Cochrane Database Syst Rev. 2004:4:CD004248.

19. Cade WT, Peralta L, Keyser RE. Aerobic exercise dysfunction in human immunodeficiency virus: a potential link to physical disability. Physiotherapy. 2004;84(7):655-664.

20. Berg KO, Wood-Dauphinee SL, Williams JI, Maki B. Measuring balance in the elderly: validation of an instrument. Can J Public Health. 1992;83 Suppl 2:S7-S11.

21. Podsiadlo D, Richardson S. The timed "Up and Go": a test of basic functional mobility for frail elderly persons. $J$ Am Geriatr Soc. 1991;39(2):142-148.

22. Karvonen MJ, Kentala E, Mustala O. The effects of training on heart rate; a longitudinal study. Ann Med Exp Biol Fenn. 1957;35(3):307-315.

23. Borg G. Psychophysical bases of perceived exertion. Med Sci Sports Exerc. 1982;14(5):377-381.

24. US Department of Health and Human Services. CD4 count. Available from: http://aids.gov/hiv-aids-basics/just-diagnosed-with-hiv-aids/ understand-your-test-results/cd4-count/. Accessed October 9, 2013.

25. Centers for Disease Control and Prevention. HIV/AIDS. Available from: http://www.cdc.gov/hiv/basics/whatishiv.html. Accessed October 9, 2013.

26. US Department of Health and Human Services. Guide for HIV/AIDS clinical care. Available from: http://hab.hrsa.gov/deliverhivaidscare/ clinicalguide 11/cg-00-00.html. Accessed October 10, 2013.

27. Batcho CS, Stoquart G, Thonnard JL. Brisk walking can promote functional recovery in chronic stroke patients. $J$ Rehabil Med. 2013;45(9):854-859.

28. Hazmat TK, Fashoyin OF. Balance retraining in post stroke patients using a simple, effective and affordable technique. African Journal of Neurological Sciences. 2007;26(2):39-48.

29. Ware JE Jr, Shelbourne CD. The MOS 36-item short-form health survey (SF-36). I. Conceptual framework and item selection. Med Care. 1992;30(6):473-483.

30. Jaquet A, Garanet F, Balestre E, et al. Antiretroviral treatment and quality of life in Africans living with HIV; 12-month follow-up in Burkina Faso. J Int AIDS Soc. 2013;16:18867.

31. Guermazi M, Allouch C, Yahia M, et al. Translation in Arabic, adaptation and validation of the SF-36 Health Survey for use in Tunisia. Ann Phys Rehabil Med. 2012;55(6):388-403.

32. Wilmore JH, Després JP, Stanforth PR, et al. Alterations in body weight and composition consequent to $20 \mathrm{wk}$ of endurance training: the HERITAGE Family Study. Am J Clin Nutr. 1999;70(3):346-352.

33. Janssen I, Katzmarzyk PT, Ross R, et al. Fitness alters the associations of BMI and waist circumference with total and abdominal fat. Obes Res. 2004;12(3):525-537.

34. Jaeschke R, Singer J, Guyatt GH. Measurement of health status. Ascertaining the minimal clinically important difference. Control Clin Trials. 1989;10(4):407-415.

35. Kamper SJ, Maher CG, Mackay G. Global rating of change scales: a review of strengths and weaknesses and considerations for design. J Man Manip Ther. 2009;17(3):163-170.

36. Joffee AM, Hallman M, Gélinas C, Herr DL, Puntillo K. Evaluation and treatment of pain in critically ill adults. Semin Respir Crit Care Med. 2013;34(2):189-200.

37. Sarzi-Puttini P, Vellucci R, Zuccaro SM, Cherubino P, Labianca R, Fornasari D. The appropriate treatment of chronic pain. Clin Drug Investig. 2012;32 Suppl 1:21-33.

38. Nadler SF. Nonpharmacologic management of pain. J Am Osteopath Assoc. 2004;104:11 Suppl 6S-12S.

39. Gélinas C, Arbour C, Michaud C, Robar L, Côté J. Patients and ICU nurses' perspectives of non-pharmacological interventions for pain management. Nurs Crit Care. 2013;18(6):307-318. 
HIV/AIDS - Research and Palliative Care

Dovepress

\section{Publish your work in this journal}

HIV/AIDS - Research and Palliative Care is an international, peerreviewed open-access journal focusing on advances in research in HIV, its clinical progression and management options including antivira treatment, palliative care and public healthcare policies to control viral spread. The journal welcomes original research, basic science, clinical \& epidemiological studies, reviews \& evaluations, expert opinion \& commentary, case reports \& extended reports. The manuscript management system is completely online and includes a very quick and fair peer-review system. Visit http://www.dovepress.com/ testimonials.php to read real quotes from published authors.

Submit your manuscript here: http://www.dovepress.com/hivaids---research-and-palliative-care-journal 